\title{
Mário de Andrade visto por Gamaliel Churata
}

Mauro Mamani Macedo

\section{Resumen}

En el presente artículo me ocuparé de analizar la recepción crítica que realiza el escritor puneño Gamaliel Churata (1897-1969) a la poesía de Mário de Andrade. Para explicar este tema, primero, preciso el carácter cosmopolita del Boletín Titikaka, que fue una revista que representaba el indigenismo de vanguardia. Luego evidenció los vínculos entre el modernismo brasilero y el vanguardismo peruano. Finalmente desarrollo el análisis de la lectura que nos presenta Gamaliel Churata a la poesía de Mario de Andrade. Haré notar lo atento que estaba Churata a la producción literaria brasilera, y en espacial a la escritura de Andrade. Observo también como estos dos escritores desde vertientes y espacios distintos, tienen un mismo objetivo: reflexionar sobre su realidad y luego producir su literatura.

Palabras clave: Mário de Andrade, Gamaliel Churata, modernismo, indigenismo, vanguardismo

\begin{abstract}
In this article I will analyze the critical reception to the poetry of Mario de Andrade that the Puneño writer Gamaliel Churata (1897-1969) does. To explain this issue, first, I specify the cosmopolitan character of the Bulletin Titikaka, which was a magazine that represented the vanguard indigenism. It showed the links between Brazilian modernism and Peruvian avant-garde movement. Finally I develope the reading analysis that Gamaliel Churata presents to the poetry of Mario de Andrade. I will show how Churata was very interested in Brazilian literary production, specially in Andrade's writing. I noted too how these two writers from different areas and aspects have the same goal: to reflect on their reality and then produce their own literature.
\end{abstract}

Key words: Mário de Andrade, Gamaliel Churata, modernism, indigenism, avant-garde movement 


\section{CARÁCTER COSIMOPOLTA DEL BOLETÍN TITHALA (PUNO, 1926-1930)}

esde el Orkopata, desde los 3800 metros sobre el nivel del mar, el grupo puneño
Orkopata tenía conexiones mundiales con escritores de diversas culturas y naciones. Brasil es uno de los países con los que establece contacto, por ello tres son los autores brasileños ${ }^{1}$ que están presentes en el Boletín. Dos con nombre propio y uno con seudónimo: Araujo Murillo, Mário de Andrade y Charles Lucifer (sed.). De Murillo se publica una reseña del libro $A$ iluminação da vida (BT: 30$)^{2}$ y un poema "La macumba zabumba» (BT 29:3), traducido por Enrique Bustamante Ballivián. De Charles Lucifer se publican dos poemas escritos en francés: «La legión des solitaries» (BT 21: 3) y «Presence» (BT 27: 4). También se encuentra a uno de los escritores más emblemáticos y prolíficos de Brasil: Mário de Andrade. De él se divulgan dos poemas en portugués extraídos del libro Clã do Jabuti, poemario que se publica en São Paulo en 1927. Los poemas que se reproducen en el Boletín Tititkaka [indomériqa-Tywanaqu], Puno-mayo-1929. Tomo II, N. XXX, son «Sambinha» y «Moda dos quatro rapazes». Años después Churata recordará la publicación de estos poemas cuando emprende una evaluación de la literatura indoamericana, escribe que: «Mário de Andrade es un buen poeta brasilero. Su nombre se repite en el grupo de "Boletín Titikaka", entre hombres dilectos» (Churata 2008 [1932]: 1). ${ }^{3}$ El objetivo del presente artículo es evidenciar la presencia de los escritores brasileros en el Boletín Titicaca, se pone énfasis en la lectura que realiza Gamaliel Churata a la obra de Mário de Andrade.

Tal como se registra, el poeta Araujo Murillo sale en dos oportunidades, con una reseña y con un poema. En la reseña de su libro $A$ iluminação da vida, se escribe que Murillo «tiene, cual el poeta ofrece en su Programa, cadencia primitiva, gritos de juventud y de fuerza, interjecciones deslumbradas. Tiene sabor interno de tierra, aliento de preocupación

1 También se reseña el libro México revolucionario de Óscar Tenorio, que se publica en Sao Pablo [Río de Janeiro] en 1928 (BT 30: 4).

2 Sigo la enumeración establecida por Cynthia Vich, en su libro Indigenismo de Vanguardia en el Perú. Un estudio sobre el Boletín Titikaka, 2000.

3 Reproducido independientemente, responsable Arturo Vilchis-México, América Nuestra-Rumi Maki, agosto 2008. Todas la citas vinculadas a este artículo estarán referidas a esta última reproducción, dejo mi agradecimiento a Arturo Vilchis quien gentilmente me proporcionó este material. Este mismo artículo de Churata se publicó primero en el Diario El Comercio de Cusco en la sección Pagina Literaria, con el título «Estaturas del sueño», el 7 de julio de 1931. Luego se edita en México con algunas variaciones. El hallazgo la primera publicación corresponde a Henry Esteba Flores. Artículo disponible en $<\mathrm{http}$ ://skepsis-wilmer. blogspot.com/>. 
popular; hace ver que el poeta viene bañado en linfa selvática y que gusta gozosamente el abalorio y la chilindrina, primeros atributos de la civilización». En la valoración del libro se evidencia que el poeta conoce el interior de su tierra esto se comprueba en la configuración de sus poemas. Para el reseñador, esto implicaría una consciencia de lo suyo y de lo propio, de allí que resalte estos vínculos con la tierra. Se reconoce el «sabor interno de tierra», la escritura que viene de adentro, de esta forma el sabor tiene que ver con lo propio, con lo identitario, con el contenido del poema, porque dejan sentir el sabor de la tierra. Esto se expresa con «la cadencia primitiva» y con la "preocupación popular». Estos enunciados dejan entrever una memoria actualizada del ritmo ancestral y la intención para que sus poemas tengan una comunidad lectora más amplia, apertura que se daría por la sencillez de la expresión. Además, esta expresión se reconoce como eufórica porque tiene juventud y fuerza, no obstante, goza del abalorio y la chilindrina, primeros recuerdos y primeras historias de una civilización. Todos estos elementos se pueden encontrar en su poema «La macumba zabumba» que aparece en el Boletín. Todo el poema configura su representación a partir de un eje musical, en torno a él, se despliega la música afrobrasileira, en un persuasivo intento de atrapar la escenificación de esta música.

Charles Lucifier ${ }^{4}$ es un poeta que ama el mundo francófono, por esta razón escribe en francés, sin dejar de querer a su tierra. Esta actitud de escribir en otro idioma, ocupándose de temas ajenos y lejanos, con destinatarios distintos y distantes de los suyos tiene que ver con la dinámica de las influencias y de las dominancias. Con las representaciones provocada por los encuentros y contactos culturales, también con los procesos de dependencia y colonización. Las cuales en el proceso literario brasilero tiene un significado especial, por esta razón, es necesario recordar el carácter cosmopolita que tenía la literatura brasileña

4 El seudónimo Charles Lucifer corresponde al poeta Antônio Dias Tavares Bastos (1900-1960). En un artículo Manuel Bandeira menciona que «Foi ao tempo do movimento modernista que apareceram os volumes do poeta, intrigando-nos a todos sob o pseudônimo estranho de Charles Lucifer. Quem seria esse luciferino vate francês perdido nos trópicos? — perguntávamos. Quando autenticamos o autor na figura pequenina, cordial e doce do brasileirinho do Espírito Santo, logo principiamos a tratá-lo por Lúcifer, com acento na primeira sílaba, porque achávamos graça de assim chamar o menos demoníaco dos homens. Lúcifer, o mais orgulhoso dos anjos, o revel por excelência e por isso precipitado no Inferno — com ele nada tinha de parecido, por mais remoto que fosse, o bom, o simples, o cândido Tavares Bastos. Um rapaz que nunca vi dizer mal de ninguém, uma criatura completamente despida de orgulho, incapaz de inveja ou de qualquer outro sentimento menos nobre» (Bandeira 1966: 292-293). Dejo expreso mi agradecimiento a Meritxell Hernando Marsal quien tuvo la generosidad de enviarme este artículo de Manuel Bandeira y la carta que envío desde Puno Diego Kunurana a Mário de Andrade. 
y las consecuencias que generó ese cosmopolitismo. Escribir en otro idioma, por esos tiempos tenía múltiples significados. Por ejemplo, uno de los significados es subestimar a la comunidad lectora local y dirigirse a una comunidad europea. Esta actitud ha demostrado una excesiva dependencia, pues no solamente adoptaba, formas de expresión externas, sino que también adopta temas y contenidos foráneos, lo hacían como si su realidad inmediata no fuese lo suficientemente valiosa para ser representada. Por esta razón, aparecen poetas, novelistas que escriben en francés. Asimismo es importante recordar que el proceso cultural y literario brasilero tuvo distintas influencias. La literatura brasileña establece primero, un diálogo con España y Portugal, luego de desprenderse de esta conexión, establece una dependencia cultural con Francia. Esta es la razón por la que muchos poetas usan este idioma con intenciones de legitimar su producción utilizando códigos de otros contextos. Algunas veces, la búsqueda del reconocimiento de lo propio tuvo un impacto positivo porque permitió asimilar la expresión externa para nutrir las formas expresivas nativas. Así, muchos escritores que tuvieron como referentes modelos a escritores en el extranjero se convirtieron en modelo para las nuevas generaciones. Otras veces, no se dio tal impacto debido al acatamiento acrítico y sumiso de las formas ajenas, ya que solo se quedaron en imitaciones burdas que no causaron ningún impacto en la tradición interior.

Todo esto tiene que ver con lo que Antonio Candido llama la dialéctica entre lo local y lo universal. Da cuenta de las influencias, afirmaciones y distanciamientos que se tienen en los distintos sistemas culturales hegemónicos o marginales. En estas dinámicas fluctuantes muchas veces se llega a posiciones vulgarmente serviles que evidencian un colonialismo del imaginario o de un acatamiento acrítico de lo exterior, como fue el caso de la academia de las letras brasileras que se organizó calcando la émula francesa. ${ }^{5}$

5 Escribe Antonio Candido que: «En su aspecto más grosero, la imitación servil de los estilos, de los temas, de las actitudes y de las prácticas literarias pueden ser actualmente de un provincianismo cómico, habiendo sido en el pasado un rasgo de pose aristocrática que servía para compensar el sentimiento de inferioridad en un país colonial. En Brasil el hecho llega a su extremo, con una Academia de Letras copiada de la francesa, instalada en un edificio que reproduce el Petit Trianon de Versailles - y Petit Trianon es, fuera de broma, su antonomasia-, con cuarenta miembros que se tildan de "inmortales" y, de acuerdo con el modelo francés, usan uniforme bordado, bicornio y espadín. Pero, en toda América, la bohemia calcada en Greewich Village o Saint-Germain-des-Prés, con una apariencia de rebeldía innovadora, puede representar muchas veces algo equivalente». Otro ejemplo de influencia para el caso brasileño es lo sucedido con el romanticismo brasileño en el cual se afirma el nacionalismo y la independencia cultural cuando un grupo de jóvenes estaba en París y fundan en 1836 la revista Niterói (Cf. Candido 1995: 382, 286). 


\section{MÁRIO DE ANDRADE VISTO POR GAMALIEL CHURATA}

Considera Candido que un país intervenido o culturalmente dependiente, muchas veces sufre imposiciones que son propiciadas por distintos factores:

La penuria cultural hizo que los escritores se volcasen hacia los padrones metropolitanos y europeos en general y constituyesen una agrupación, en cierto modo, aristocrática con relación al hombre inculto. En efecto, en la medida en que no exista un público local suficiente, el escritor escribia como si su público ideal estuviese en Europa y, de esta forma, muchas veces se disociaba de su tierra. Esto daba origen a obras que los autores y lectores consideraban altamente refinadas por el hecho de que asimilaban las formas y valores de la moda europea pero que, por falta de puntos referenciales, podían no pasar de ejercicios de mera alienación cultural, que ni siquiera la calidad de la realización logra justificar (Candido 1995: 375, el resaltado es nuestro).

Una posición radicalmente contraria también es negativa, tal como lo señala Candido. Esta actitud nos llevaría a un provincianismo cultural, es decir, no se puede afirmar lo nativo ciegamente, sin atender a las dinámicas culturales externas, encerrarnos en sustancialismos vanos. Es recomendable asumir estas influencias a partir de la consciencia de la realidad cultural de cada nación. Con esta consideración, se puede realizar un proceso de asimilación positivo o realizar el acto consciente de «absorber a los otros para ser absorbido" como plantea Churata (1957:11). ${ }^{6}$ Es decir, poseer algo para trasladar nuestras sustancialidades e hibridarlas y avanzar hasta ser dominantes en el nuevo cuerpo.

En la publicación de los trabajos de Charles Lucifer se llama la atención sobre estos fenómenos que tienen que ver con las naturales dinámicas que una cultura muestra cuando se abre al mundo con una actitud cosmopolita. Esto se hizo en la literatura brasileña y corrió los riesgos naturales de todo contacto cultural de ser asimilada hasta ser servil o asimilar las formas y técnicas de expresión que permitan enriquecer la escritura nativa.

Consideramos que la intención de Charles Lucifer fue más sincera y menos de moda, es más, podemos afirmar que diferente y hasta contraria al colonialismo del pensamiento,

6 «De paso anotemos tales estupendas revelaciones que el historicismo no há olisqueado, si nada conforma como no sea el contenido sustancioso de la política del inka, el cual, cuando colonizaba, si absorvía un pueblo era para hacerse absorver por él en el grado ése en que el colono acaba en representativo categorial de su espíritu» (Churata 1957:11). Si bien es cierto que este concepto es utilizado para otros contextos, considero que es aplicable para este caso, en forma algo similar a la idea que tenían los integrantes del movimiento de antropofagia de Brasil o al canibalismo cultural. 
porque que si bien quería mucho a la cultura francesa este nuevo amor no impidió el seguir amando a su país, ya que este poeta se distinguió de otros poetas brasileros quienes escribían en francés tal como lo distingue Manuel Bandeira: «Os seus versos franceses não são como os da quase totalidade dos brasileiros que se metem a poetar em francês. A prosódia poética de Tavares Bastos obedecia rigorosamente aos cânones banvillianos» (Bandeira 1966: 292293). Una clara muestra de que no pertenece a esta dependencia es que no solamente trae elementos culturales de otras naciones sino que cuando viaja a Francia difunde la poesía brasileña. Así publica, en 1954, la Anthologie de la poésie brésilienne contemporaine. Esta acción de difundir lo propio en otros contextos expresa cuanto quería a su tierra y niega toda actitud sumisa, parece estar en la posición de un intelectual que trae y lleva contenidos culturales de ambas naciones.

\section{IVODERNISIMO BRASILEÑO Y VANGUARDISMO PERUANO}

Parafraseando a Candido, diremos que el modernismo brasileño y el vanguardismo
peruano constituyen dos momentos decisivos en nuestras literaturas. Para el caso brasileño se produce la afirmación y el conocimiento de lo propio; una literatura que se desprende de dos procesos de exploración: una exploración de sus pasos que los retorna al interior de su tierra y una exploración de las formas de la expresión que permiten que las sustancias y las formas se vean renovadas. Para el caso peruano, el vanguardismo significó uno de los desarrollos más altos y, específicamente, para el caso del vanguardismo indigenistas significó la más alta expresión literaria que fue acompañada de un conocimiento de lo nuestro, un hurgar en nuestras raíces y una afirmación de nuestra identidad. A esto se suma un programa político-ideológico presente en el grupo Okorpata. Los manifiestos, los ensayos, los poemas, los libros que se publicaron en los años veinte dan cuenta de esta actitud. Citemos solo tres ejemplos Ande (1926) de Alejandro Peralta, Falo de Emilio Armaza (1926) y 5 metros de poema (1927) de Carlos Oquendo de Amat. Los tres poetas publicaron en el Boletín Titikaka. En los tres libros se puede ver una preocupación por representar la realidad andina, pero con una forma de expresión renovada, innovadora, fresca que rompía con todos los convencionalismo de la lógica. Así, la morfología de las palabras sufre transformaciones, las líneas se tuercen, los signos de puntuación brillan por su ausencia, la página en blanco empieza a hablar y compite con las palabras; no obstante, todo este experimentalismo verbal no se desancló nunca de lo propio. 


\section{MÁRIO DE ANDRADE VISTO POR GAMALIEL CHURATA}

Entonces tanto el modernismo brasileño como el vanguardismo peruano tienen elementos vinculantes, por esta razón, consideramos que Cinhya Vich acierta al aclarar que «es importante evitar uno de los errores más frecuentes en los estudios sobre vanguardia continental: la artificial y tergiversadora separación entre el 'modernismo' brasilero y la vanguardia de los países de habla hispana» (Vich 2000: 237). Puesto que:

Como es conocido, el modernismo brasilero no solo es considerado por muchos como el iniciador del movimiento vanguardista en América Latina (a partir de la famosa «semana de Arte moderno» de 1922), sino que constituye uno de los focos más interesantes y de mayor fuerza en cuanto a la renovación estética e ideológica del continente. Como ocurrió en los países de habla hispana, la vanguardia brasilera también se caracterizó por ser un proyecto de cultura dedicado a examinar críticamente el problema de la identidad nacional en el contexto de la modernización. (Vich 2000: 237)

Vich se refiriere a «A Semana da Arte Moderna (São Paulo, 1922) foi realmente o catalizador da nova literatura, coordenando, graças ao seu dinamismo e à ousadia de alguns protagonistas, as tendências mais vivas e capazes de renovação, na poesia, no ensaio, na música, nas artes plásticas». ${ }^{7} \mathrm{El}$ modernismo brasileño tuvo como objetivo realizar una revisión de los planteamientos críticos del romanticismo, asimismo, tenía como intención central la afirmación de la identidad a partir del reconocimiento de los valores auténticamente nacionales. El espíritu brasileño debía estar cifrado en su producción artística, por ello, se incorpora la manifestación folclórica y la cultura popular.

Esta evaluación de la realidad se presentó en ambos países, cuando la modernización empezó a desarrollarse. De allí que en el universo de los poemarios hay representación de lo propio, pero también hay en su universo configurativo: máquinas, aviones, trenes, aeroplanos, motores. Elementos nuevos que no pueden dejar de someterse a un proceso de naturalización, así el tren será un animal.

\section{CONTEXTO DE PRODUCCIÓN DEL POEMARIO}

os años 1926 y 1927 son importantes en la producción literaria de Mário de Andrade,
ya que gesta dos libros importantes. Macunaima, una de las obras más simbólicas para

7 En «Literatura e cultura de 1900 a 1945 (panorama para estrangeiros)». Disponible en <www.pacc.ufrj.br/ literaria/estrangeiro.html>. Consulta hecha en 24/08/2009. 
Brasil y reconocida por su originalidad en todo el mundo. Esta novela fue escrita en unas vacaciones en 1926, en seis días, luego se pule en 1927 y fue publicada en 1928. En este tiempo también se escribe y se publica Clã do Jabuti. ${ }^{8}$ A este libro pertenecen los dos poemas que se publican en el Boletín Titikaka.

Mário de Andrade junto con Oswald de Andrade y otros poetas modernistas realizan en la Semana Santa de 1924 el famoso viaje del descubrimiento de Brasil. Su destino era Minas Gerais. Durante este viaje, Andrade, recoge un valioso material de música y de poesía oral, todo ello sería aprovechado en su libro Clã do Jabuti. En esa época, enfatiza su interés para conocer Brasil, así investiga sobre los mitos y las leyendas. Elementos que le servirán para crear su literatura. En una carta dirigida a Manuel Baindeira, menciona que:

[...] de hecho conociendo la formación primitiva de las nacionalidades, lo mucho que importan la temática legendaria nacional, porque resalta los caracteres psicológicos, y sabiendo más acerca de lo que habían hecho en su lieds, Goethe, Heine, Lenau, etc., tuve intención de proseguir, abrasileńándolo, el proceso cantador de esos alemanes (19-3-1926) (Andrade 1979: 464).

En 1927, entre los meses de mayo y agosto, realiza otro viaje al norte de Brasil. A esto, él llama pasar a una etapa primitiva, busca el sentimiento de lo profundamente brasileño. En su visita por el interior, entendió que las distintas manifestaciones culturales con las que iba conviviendo eran serias y organizadas, tal como apunta Gilda de Mello. Esto lo aclara en otra carta dirigida a Alceu Amoroso Lima.

Yo sé perfectamente que soy un primitivo pero ya dije en qué sentido lo soy. Soy primitivo porque soy protagonista de una etapa que empieza. Esto no quiere decir falsa ingenuidad ni ignorancia ni abandono de cultura. Soy primitivo como se puede hablar y se dice que los trovadores provenzales fueron primitivos, como la escuela siciliana fue primitiva, como Giotto fue primitivo, toda gente que se cultiva. Por lo demás [...] primitivo es una palabra como mística, palabra que

8 Desde el título del poemario de Mário de Andrade se puede ver catafóricamente lo que vendrá, así lo explica Ana Rosa Mendonça Nunes: «Em Clã do Jabuti, vemos um Mário de Andrade que, mesmo escrevendo em São Pablo, quer sentir todo o Brasil. Essa intenção do poeta já se apresenta no titulo da obra-e se desdobra ao longo dos títulos dos poemas que compóem o livro. A idéia de clã pressupóe união, família, e o jaboti surge em quanto representaçáo de um animal tipicamente nacional presente em muitas lendas. É justamente essa significação que o livro de Mário sugere: reunir a família brasileira, a nação, aquela que caminha a passos lentos de jabuti» (Cf. Mendonça Nunes 2006: 10). 


\section{MÁRIO DE ANDRADE VISTO POR GAMALIEL CHURATA}

no tiene sentido. Fíjate que llamo primitivo a los dibujantes de las cavernas de Altamira, gente que seguramente constituía ya la culminación de una civilización y, sin duda, los dibujantes más desarrollados y más cultos de aquellos tiempos. (23-11-1927). (Andrade 1979: 469-470)

En este contexto de búsqueda del conocimiento de Brasil profundo, primero a través del estudio de los textos que tratan de lo legendario, luego con una constatación más directa en un trabajo casi antropológico, es que escribe su libro de poesía Clã do Jabuti, como lo dice Gilda de Mello, casi todos los poemas reflejan esta orientación (Cf. 1979: 466)

\section{Gamaliel Churata lector de Mário de Andrade}

Camaliel Churata dedica una gran atención a los poemas Mário de Andrade

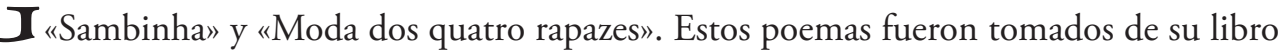
Clã do Jabuti, ${ }^{9}$ que se publicó en São Paulo, 1927. Estos poemas fueron reproducidos en el Boletín Tititkaka [indomériqa-Tywanaqu], Puno-mayo-1929, Tomo II, N. XXX. Este es el primer momento de la divulgación de la poesía de Andrade. En 1932, nuevamente, Churata se ocupará de su poesía. En su artículo "Aspectos de la literatura indoamericana» (1932), le dedica un comentario donde lo primero que deja claro es que «Mário de Andrade es un buen poeta brasilero». Agrega que:

Pero Andrade, además de poeta es un crítico y un trabajador honesto. Crítica, poesía, cuento, novela, todo es materia de actividad para él, y en que él es un trabajador, un trabajador espontáneo y alegre. Su producción es ya numerosa. En crítica ha dado dos o más estudios sobre musicografía brasilera, varios libros de cuentos y una novela, que él llama rapsodia «Macunaima». Sus poemarios son numerosos. Y el último de ellos «Remate de Males», nombre de pila con bastante dosis de humorismo romántico. (2008 [1932]: 2)

La afirmación que formula Churata es porque conoce la calidad y la cantidad de trabajos realizados por el poeta. Ya que para entonces Mário de Andrade había escrito varios libros: sobre crítica, A escrava que não é Isaura(1925); dos libros de Música: Ensaio

9 La recepción de este libro y así como el de Macunaima, es agradecido por la Editorial Titikaka, mediante una carta que envía Diego Kunurana a Mário de Andrade (ver anexo). Diego Kunurana es el seudónimo de Demetrio Peralta Miranda, hermano de Gamaliel Churata (Arturo Peralta Miranda) y de Alejandro Peralta. Muchos de sus trabajos sirvieron para ilustrar el Boletin Titikaka. 
sobre música brasileira (1928) y Compêndio de História da Música (1929); en cuento tenía a Primero andar (1926) y, en poesía, ya publicados los siguientes libros: Há uma gota de sangue em cada poema (1917), Paulicéia desvariada(1922), Losango cáqui (1226), Clã do jabuti (1927) y Remate de males (1930). También publica su novela Macunaima (1928).

Este juicio lo acredita con la lectura del libro de Enrique Bustamante Ballivián: ${ }^{10}$ «En una elegante traducción de nueve poetas, Bustamante Ballivián, los mejores productos de esta lírica original y muchas veces vigorosa. Con esa traducción se puede llegar a apreciaciones certeras respecto del fenómeno americano del Brasil. Junto a sus brillantes camaradas, Mário de Andrade destaca con atributos inconfundibles y se puede establecer su valor neto». (2008 [1932]:32). Churata singulariza la producción de Mário de Andrade, ya que de los nueve poetas es el único que es motivo de comentario, por lo tanto, asumido como representante de la poesía brasileña de entonces.

En un artículo que se publica en México en 1932, "Aspectos de la literatura indoamericana», comenta dos libros de poesía: Clã do jabuti y Remate de males. Sobre Clã do jabuti sostiene que es un libro precioso, donde «la nota saudosa tiene momentos de una poderosa virtualidad de sugerencia». Es grande el aprecio que tiene por este poemario, ya que conserva en la memoria los versos de uno de los poemas que publica en el Boletín «Moda dos quatro rapazes» y menciona que «Apenas conozco nada la sensación hilativa de la sociedad fantasmal como ese poema ingenuo». El poema expresa ese amor de una sociedad íntima de amigos, amigos y hermanos que delatan los lazos afectivos y muestran un temor a amar. Allí se advierte la presencia amenazadora de la mujer pues su ingreso a esta sociedad puede trastocar todo. ${ }^{11}$ Encuentra en el libro lo fuerte y lo tierno que hay en el ayllu, interpretación donde asimila el libro a su referente cultural andino, pues homologa las características del ayllu al libro, luego es un libro-ayllu. «Entiendo que Clã do jabuti es a nosotros, sobre materia e intención tanto como poesía, fortaleza y ternura de ayllu». Ayllu

10 El libro al que se refiere Churata es 9 poetas de de Brasil, publicado en 1930. Estos poetas son Guillermo de Almeida, Mário de Andrade, Manuel Bandeira, Ronald de Carvalho, Gilka Machado, Cecilia Meirelles, Ribeiro Couto, Murillo Araujo, Tasso da Silveira. En esta antologia aparece el poema Zambiña de mario de Andrade y «La Macumba-Zabumba» de Murillo Araujo, que se publica en el Boletín Titikaka. Es claro que quien los mantenía al tanto de la producción literaria brasileira es Enrique Bustamante Ballivián, así lo reconoce Diego Kunurana en la carta que le envía a Mário de Andrade en agradecimiento al envío de sus libros. Esto último prueba la comunicación directa y fluida que se establecía entre los miembros del Boletín y los autores brasileros. «El sr. Enrique Bustamante Ballivián nos había hablado ya de usted; de manera que conocer sus libros ha sido realizar el cumplimiento de un deseo largamente deseado». (Ver anexo).

11 Una interpretación en este sentido se encuentra en Rodrigues DE Sousa (2006: 92-98). 


\section{MÁRIO DE ANDRADE VISTO POR GAMALIEL CHURATA}

es la comunidad andina que estaba integrada por varias familias, los unía un tronco común del cual descendían. Dentro del ayllu había cooperación y afectividad. De allí ese carácter fuerte. Estas características del ayllu son usadas para calificar el libro de Andrade. Un libroayllu. Agrega que «Pero si el libro quiere dar tal alimento campestre no está exento de jugos urbanos». Así e libro según Churata asimila en su representación lo campestre y lo urbano, entonces trasciende esa oposición de rural:campo/urbano:ciudad, porque los comprende en su representación. Esta es una marca de objetividad de su juicio ya que no solo resalta lo vinculante al mundo rural, sino evidencia todos los otros elementos que están representados en el libro.

Destaca la maestría en los juegos y las travesuras gramaticales, dice que «Hácese preciso mucha ingenuidad, o sea pureza y rico sistema arterial, para organizar esta danza donde se ven fetos de cinco meses». Andrade establece ese juego con el lenguaje que es una muestra del esfuerzo para expresar y atrapar el movimiento con las palabras, también a través de la ambigüedad trata de insinuar nuevas sensaciones destiladas al lector atento.

Otro tema que destaca Churata es su humorismo propio e innovador

Este humorismo es ancho y optativo, digamos mejor, no es un humorismo de alquimia, fruto de una filosofía de un sistema de interpretación final. El humorismo de Eca de Queiroz, Mark Twain, Bernard Shaw, representa lo que se ha dado en llamar flor de raza, un humorismo elegante no libre de ironía, forma última de la debilidad. El humorismo de Andrade — y por esta razón me entusiasma — es un humorismo infantil si se quiere, libre de toda erosión patológica. (2008 [1932]: 3)

Churata distingue el humor fabricado, elaborado, un humor de laboratorio que por ese planeamiento ya llegada frío al lector, y por eso mismo no deja de ser tentado por la ironía o el sarcasmo, pues dará a conocer ideas diferentes a las expresadas en un acto cómico. Churata apuesta por un humor más sincero, ingenuo e infantil, por ello más sano, que esté libre de toda anormalidad. Este último humor es el que encuentra en la poesía de Andrade.

Destaca la visión ingenua del mundo, ya que esta capacidad le permite el asombro ante la novedad, sorprenderse del mundo exterior y de la fascinación por lo nuevo. «En él existe una constante preocupación por la novedad del mundo, su descubrimiento cobra sensación subitánea "Meu pensamento assombra mundos novos" "Esta misma visión ingenua le permite una consciencia igualitaria. "Una vaga conciencia igualitaria, especie de melodioso escenismo, fruto igualmente, a mi juicio, de esa visión ingenua del mundo, 
le hace sentirse igual a todos, pero elevado a una categoría superior. "E me sinto maior, igualando-me aos homens iguais"» (2008 [1932]: 3). Así, Churata reconoce una poesía diáfana, hecha con la ingenuidad y la sinceridad con la que los niños descubren las nuevas cosas del mundo.

El otro libro que comenta es Remate de males, afirma que el poemario tiene «nombre de pila con bastante dosis de humorismo». En el poemario encuentra la nostalgia, pero no monótona, sino humorística, gimnástica y saludable. «La saudade ese estado de ánimo tan exclusivo del idioma lusitano, surge en este libro en forma bella y suscitadora, pero no ya en la perspectiva monótona del tono elegiaco, sino aligerada en el relente de un humorismo saludable y gimnástico» (2008 [1932]: 2).

Encuentra también en este poemario la sencillez, la emoción infantil y el valor de la lengua portuguesa para expresarlo. "Creo que en pocas lenguas se pueda decir con mayor sencillez que en portugués, cuando el poeta se propone dar una emoción infantil. "Morto suavemente ele repousa sobre as flores do caixao" [...] La sencillez de la imagen va pareja con la vitalidad de la palabra escueta. Hay cosas dichas allí con la ternura y simpleza inolvidables» (2008 [1932]: 4).

Sobre el proceso de producción del libro nos informa que «En este libro están compiladas composiciones de los años 24 y 30; por tanto su escrita tendencia más clasista se remoza con libres intenciones que no llegan, sin embargo, al inarticulado ni al antiritmo». Churata argumenta la organicidad del libro no obstante la distancia temporal en la que se ha escrito. Remate de males no es una simple compilación de poemas, sino que hay elementos que los hilvana, los articula. Encuentra un ritmo que atraviesa todos los poemas. Esta organicidad del libro no ha sido socavada por el tiempo. Churata considera que Mário de Andrade es un poeta de raíz musical, por el manejo del ritmo al escribir. Esta virtud en la escritura ya fue advertida en el libro anterior Clã do jabuti, donde se encuentran poemas que parecen ensayos de y sobre la música. Aquí es pertinente recordar que Andrade recibió una rigurosa formación en música, además dictó cátedras sobre esta disciplina, entonces, no solamente la estudió sino que la practicó. Considero que allí el juicio de Churata es certero. Esto se debe al profundo análisis de los textos. Sin embargo, Churata como todo crítico honesto con su función intelectual, con su ética de crítico muestra su objetividad al momento de juzgar, ${ }^{12}$ encuentra que el apego a la música de Andrade lo lleva a cometer

12 Antonio Candido en uno de sus ensayos menciona que siempre al crítico se le pide que defina la crítica, que 


\section{MÁRIO DE ANDRADE VISTO POR GAMALIEL CHURATA}

errores: "Y siendo musical cae (desgraciadamente es una caída) en el fraseo descuidando el valor unigénito e intrínseco de la palabra en sí, secreto y omega del poema eterno» (2008 [1932]: 4). En esta apreciación, Churata muestra su carácter objetivo, pues no cae en la pura celebración, deja ver sus ideas sobre el poema y la poesía en sí, el valor divino y propio de las palabras, el contenido, el significado, pues no solamente utilizar las palabras por lo que suenan o por lo bien que encajan en el poema, sino prestar atención también a su significado, al valor en sí, al contenido que alojan.

No obstante ello, el poemario es muy valioso «La visión fotogénica, el canto estupro y el pindárico atabal, concitan en sus centros motrices la sinfonía, la tendencia a la creación musical: "Grito imperioso de brancura en mim..."13 Canta a la tierra de su América en mensaje jocundo, nunca más viril y tónico que cuando la busca en la promisoria perspectiva del Futuro. América es, no obstante, para el poeta es fuerte milagro de interpretación racial, ápice del mundo, y no lo que para los pensadores proletarios: lontananza purificada en la revolución» (2008 [1932]: 4). Para Churata este libro es visto como un instrumento hermenéutico de la realidad brasileńa, y además se extiende a toda América. También resalta una de las funciones básicas de la literatura, interpretar la realidad. Aquí se interpreta el tema del racismo. En esta realidad representada, hay un grito esperanzador de futuro.

Del comentario de estos dos libros y, en específico, de los poemas y temas podemos inferir preocupaciones valiosas de Gamaliel Churata. Primero, está atento a las publicaciones extranjeras. Esta actitud demuestra el respeto y reconocimiento por la producción literaria y cultural de todos los pueblos. Segundo, no solo se informa sino que estudia y emite juicios de valor sobre esta producción literaria. Tercero, evidencia cómo a través de la lectura se establece el diálogo cultural. Cuarto, recordemos que Churata es un intelectual autodidacta, pues no recibió formación superior alguna, no obstante, ha opinado e investigado con rigor académico y ha sido muy influyente para el proceso cultural boliviano y peruano. Churata

muestre sus instrumentos, considera Candido que se debería de cambiar de pregunta, entonces se debería interrogar al crítico por su ética, por sus principios que no traicionará. Pues no es suficiente que un lector esté delante de un hombre de buena comprensión, sino también que este delante de un hombre de buena fe (Cf. Candido 2002: 23-30).

13 Este mismo verso, desde otra perspectiva que evalúa el proceso literario brasileño, es visto por Antonio Candido como una afirmación de los componentes europeos en la formación de la literatura brasilera. «[...] que exprime, sob a forma de um desabafo individual, uma ânsia coletiva de afirmar componentes europeus da nossa formaçáo». En «Literatura e cultura de 1900 a 1945 (panorama para estrangeiros)». Disponible en <www.pacc.ufrj.br/literaria/estrangeiro.html>. Consulta hecha en 24/08/2009. 
era un intelectual que desplegó su labor crítica, básicamente, en el Collao. Desde allí la extendió a todo el mundo.

La visión cosmopolita que estableció el Boletín Titikaka tuvo como guía y mentor a Gamaliel Churata, hombre visionario e iniciador de tantos temas. Esta dinámica del diálogo mundial no era una simple comunicación, intercambio o canje mecánico de libros y revistas, asistido por un espíritu de coleccionista, sino por el contrario, representaba una sincera intensión para conocer las otras literaturas. Donde se vivía un interés creciente para afirmar lo propio a partir de su conocimiento, de hurgar en las raíces sin caer en "provincianismos culturales» sino estar atento a las influencias mundiales. Esta consonancia permite nutrir las literaturas receptoras que realizan procesos de apropiación lícitos en beneficio de la expresión nativa, pues generaron una literatura muy proteica. Tanto Mário de Andrade como Gamaliel Churata estaban en ese «viaje al interior». Al interior de Brasil, Andrade; al interior de Perú, Churata. Hay que recordar que ambos sufrieron el proceso de influencia que los llevó hasta la dependencia externa esto en la forma de la expresión, un ejemplo son los poemas modernistas de Churata, ${ }^{14}$ y en la primera literatura engolada de Andrade. Luego reorientaron su destino a lo nativo, elección que fue provocada por el conocimiento profundo de sus realidades, lo que le permite una afirmación desde el ñuñu, como decía Churata. Entonces generaron una literatura que deja ver el trabajo antropológico, ya que su literatura sugería y documentaba.

14 Me refiero a los poemas que publica en La Tea (Juan Cajal, 1917) y en La Voz del Obrero (Arturo Peralta, 1915). 
Poemas de Mário de Andrade publicados en el Boletín Titikaka:

MODA DOS QUATRO RAPAZES

A Couto de Barros

[Campos de Jordão]

Nós somos quatro rapazes

Dentro duma casa vazia.

Nós somos quatro amigos íntimos

Dentro duma casa vazia.

Nós somos ver quatro irmãos

Morando na casa vazia.

Meou Deus! Si uma saia entrasse

A casa toda se encheria.

Mas era uma vez quatro amigos íntimos...

\section{SAMBINHA}

Vêm duas costureiras pela rua das Palmeiras.

Afobadas braços dados depressinha.

Bonitas Senhor! Que até dão vontade pros homens das ruas.

As costureirinhas vão explorando perigos...

Vestido é de seda.

Roupa braça é de morim

Falando conversas fiada

As duas costureirinha passam por mim

- Você vai

$$
\text { - Não vou não! }
$$

Parece que a rua parou pra escutá-las. 
Nem trilhos sapecas

Jogam mais bondades um pro outro.

E o sol da tardinha de abril

Espias entre as pálpebras sapiroquentas de duas nuvens.

As nuvens são vermelhas.

A tardinha cor-de-rosa.

Fique querendo bem aquelas duas costureirinhas...

Fizeram-me peito batendo

Tão bonitas, tão modernas, tão brasileiras!

Isto é...

Uma era ítala-brasileira.

Outra era áfrica-brasileira

Uma era branca

Outra era preta.

\section{Carta enviada por Diego Kunurana a Mário de Andrade ${ }^{15}$}

Puno 2 de agosto de 1929

Señor Mário de Andrade

Rua Lopes Chaves, 108

Distinguido compañero

Tenemos en nuestro poder vuestros hermosos libros «Clan do Jabotí» y «Macunaima». Por tal excelente obsequio que nos permite conocer un temperamento literario tan bien nutrido como el suyo, tenemos que darle las más vivas gracias.

El sr. Enrique Bustamante Ballivián nos había hablado ya de usted; de manera que conocer sus libros ha sido realizar el cumplimiento de un deseo largamente deseado.

15 Reitero mi agradecimiento a Meritxell Hernando Marsal, quien tuvo la gentileza de facilitarme este documento. La carta tiene las siguientes características: está escrita en un papel verde hecho para la editorial. En la parte superior derecha, en verde, está impreso: Boletín Titikaka Circulación Continental. La carta se encuentra en Instituto de Estudos Brasileiros de la Universidade de Sáo Paulo. 


\section{MÁRIO DE ANDRADE VISTO POR GAMALIEL CHURATA}

Leeremos despacio sus libros y lograremos dar algunas traducciones de ellos para que sean conocidos en el Perú.

Mientras tanto rogamos a usted que se sirva de considerarnos sus amigos y tener presente que «Boletín Titikaka» recibirá con sumo agrado siempre sus cartas y versos.

Firma el secretario

Diego Kunurana

Nota: sería usted tan amable de enviarnos su retrato? 


\section{Bibliografía}

Andrade, Mário de

1979 Obra escogida. Novela-cuento-ensayo-epistolario. Caracas: Biblioteca Ayacucho.

Bustamante Vallivián, Enrique

19789 poetas del Brasil. Lima: Centro de Estudios Brasileros. [Esta es una reproducción de la antología que publicó Enrique Bustamante Ballivián en 1930].

Callo Cuno, Dante y Juan Alberto Osorio (comps.)

1997 Boletín Editorial Titikaka. Edición facsimilar. Arequipa: Universidad Nacional de San Agustín.

Candido, Antonio

2002 Textos de intervenção. Selección, presentación y notas de Vinicius Dantas. 2 vols. São Paulo: Duas cidades.

1985 «Literatura e cultura de 1900 a 1945 (panorama para estrangeiros)». Disponível en $<$ www.pacc.ufrj.br/literaria/estrangeiro.html>. Consulta hecha en 24/08/2009.

1995 Ensayos y comentarios. México: Fondo de Cultura Económica.

Churata, Gamaliel

2008 [1932] «Aspectos de la literatura indoamericana». En Crisol, N. 38, febrero. [Reproducido independientemente, responsable Arturo Vilchis-México, América Nuestra- Rumi Maki, agosto 2008].

1957 El pez de oro. La Paz: Editorial Canata.

Kunurana, Diego

1929 «Carta dirigida por Diego Kunurana a Mário de Andrade». Puno 2 de agosto de 1929. [Diego Kunurana firma como secretario].

Bandeira, Manuel

1966 «Figura ímpar na década de 20 é a de Antônio Dias Tavares Bastos(1900-1960), de que Manuel Bandeira dá notícia na crônica "Coração de criança”". En Andorinha, andorinha, pp. 292-293. 
Mello e Souza, Gilda de

1979 «Selección, prólogo y notas». Mario de Andrade. Obras escogida. Noela-cuentoensayo-episolario. Caracas: Biblioteca Ayacucho.

Mendonça Nunes, Ana Rosa de

2006 Modernismo e tradição da oralidade na poesia uma leitura de Clã do Jabuti de Mario de Andrade, e Catimbó de Ascenso Ferreira. Disponible en <http://bdtd.bczm.ufrn. $\mathrm{br} /$ tedesimplificado//tde_busca/arquivo.php?codArquivo=706>. Consulta hecha en $22 / 08 / 2009$.

Rodrigues de Sousa, Cristine

2006 Clã do Jabuti uma partitura de palavras. São Paulo: Anne Blume.

VICH, Cynthia

2000 Indigenismo de Vanguardia en el Perú. Un estudio sobre el Boletín Titikaka. Lima: Fondo Editorial de la Pontificia Universidad Católica del Perú. 